Arq. Bras. Med. Vet. Zootec., v.68, n.4, p.919-926, 2016

\title{
Troponina I como biomarcador de lesão cardíaca em cães com sepse
}

[Troponin I as a biomarker of cardiac injury in dogs with sepsis]

\author{
C.S. Pereira ${ }^{1}$, R.A.L. Muzzi ${ }^{1}$, V.C. Figueiredo ${ }^{1}$, L.A.L. Muzzi ${ }^{1}$, G. Oberlender $^{2}$, \\ A.C.C.L. Júnior ${ }^{1}$, M.L. Neto ${ }^{3}$, M.M. Oliveira ${ }^{1}$ \\ ${ }^{1}$ Universidade Federal de Lavras - UFLA - Lavras, MG \\ ${ }^{2}$ Instituto Federal do Sul de Minas-IFSULDEMINAS - Muzambinho, MG \\ ${ }^{3}$ Universidade Católica de Minas Gerais - PUC Poços de Caldas - Poços de Caldas, MG
}

\begin{abstract}
RESUMO
Avaliou-se a troponina I como biomarcador de lesão cardíaca na sepse, além de outros parâmetros hematológicos, em cadelas com piometra. Os grupos avaliados não diferiram estatisticamente na avaliação da concentração sérica da troponina I cardíaca. A quantidade total de leucócitos $\left(\mathrm{mm}^{3}\right)$ e a porcentagem de bastonetes foram significativamente maiores no grupo sepse $\left(23.221,74 \pm 16.848,80 \mathrm{~mm}^{3}\right.$ e $5,91 \pm 10,18 \%)$ quando comparado ao grupo não sepse $\left(14.492,86 \pm 6.828,26 \mathrm{~mm}^{3}\right.$ e $\left.1,93 \pm 1,64 \%\right)$ e ao grupo controle $\left(10.320,00 \pm 3.999,02 \mathrm{~mm}^{3}\right.$ e $\left.1,65 \pm 2,05 \%\right)$. Houve diferença significativa nas concentrações séricas da proteína $C$ reativa $(\mathrm{mg} / \mathrm{dL})$ no grupo sepse $(19,57 \pm 41,69 \mathrm{md} / \mathrm{dL})$ se comparado ao grupo não sepse $(10,29 \pm 12,02 \mathrm{mg} / \mathrm{dL})$ e ao grupo controle $(3,60 \pm 3,53 \mathrm{mg} / \mathrm{dL})$. Na avaliação da concentração sérica do lactato, houve diferença significativa entre cães com piometra e cães saudáveis, porém não houve diferença significativa entre os grupos sepse e não sepse. Os resultados do presente estudo indicam que a troponina I cardíaca não pôde ser considerada um biomarcador precoce para injúria miocárdica nos casos de cadela com piometra, pois os resultados das mensurações foram semelhantes entre os grupos, o que indica que pode não ter ocorrido lesão dos cardiomiócitos nessa fase. Já a proteína $\mathrm{C}$ reativa e o lactato são possíveis marcadores para inflamação sistêmica, uma vez que demonstraram concentrações séricas significativamente maiores em cadelas com piometra.
\end{abstract}

Palavras-chave: cão, sepse, biomarcadores

\begin{abstract}
Troponin I as a biomarker of cardiac injury in sepsis, and other hematological parameters in female dogs with pyometra were evaluated. The groups did not differ in the assessment of serum cardiac troponin I. The total amount of leukocytes (mm3) and percentage of band cells was significantly higher in the sepsis group $\left(23,221.74 \pm 16,848.80 \mathrm{~mm}^{3}\right.$ and $\left.5.91 \pm 10.18 \%\right)$ compared to the non-sepsis group $\left(14,492.86 \pm 6,828.26 \mathrm{~mm}^{3}\right.$ and $\left.1.93 \pm 1.64 \%\right)$ and the control group $\left(10,320.00 \pm 3,999.02 \mathrm{~mm}^{3}\right.$ and $1.65 \pm 2.05 \%$ respectively). There were significant differences in serum concentrations of C-reactive protein $(\mathrm{mg} / \mathrm{dL})$ in the sepsis group $(19.57 \pm 41.69 \mathrm{md} / \mathrm{dL})$ compared to the non-sepsis group $(10.29 \pm 12.02 \mathrm{mg} / \mathrm{dL})$ and control group $(3.60 \pm 3.53 \mathrm{mg} / \mathrm{dL})$. In the evaluation of serum lactate concentration, there was a significant difference between dogs with pyometra and healthy dogs, but there was no significant difference between the sepsis and non-sepsis groups. The results of this study indicate that troponin I could not be considered an early biomarker of myocardial injury in cases of dogs with pyometra, because the results of the measurements were similar between groups, inferring that there may not have been an cardiomyocytes injury at this stage. C-reactive protein and lactate are potential markers for systemic inflammation, as demonstrated by significantly higher serum concentrations in dogs with pyometra.
\end{abstract}

Keywords: dog, sepsis, biomarker

Recebido em 22 de agosto de 2015

Aceito em 15 de dezembro de 2015

E-mail: camilinhasp19@hotmail.com 


\section{INTRODUÇÃO}

Sepse é definida como a resposta inflamatória sistêmica desencadeada por uma infecção bacteriana, viral, fúngica ou pela presença de protozoários associada a sinais de repercussão sistêmica (Rabelo, 2012), já a disfunção orgânica é conhecida como sepse grave (Abraham et al., 2000).

Os efeitos da sepse sobre o sistema cardiovascular podem ser predominantes, ocorrendo, dessa forma, quadro clínico característico de depressão miocárdica, uma das principais causas de morte em cadelas com piometra (Maretta et al., 1989).

Devido aos efeitos sistêmicos potencialmente letais induzidos pela doença, a utilização de marcadores prognósticos de morbidade, mortalidade e identificação da sepse apresenta grande demanda na medicina veterinária (Hagman, 2014).

A troponina I é uma proteína encontrada em fibras musculares esqueléticas e cardíacas responsáveis pela contração muscular (Hamacher et al., 2015; Sheyin et al., 2015; Tiruvoipati et al., 2012). A troponina I cardíaca é encontrada apenas no coração, sendo expressa exclusivamente pelo miocárdio, e está especialmente associada às miofibrilas, embora pequenas quantidades estejam presentes também no citosol (Dunn et al., 2008). Normalmente não são detectáveis na circulação por estarem presentes em pequenas quantidades. No entanto, quando há um dano à célula do miocárdio, a troponina é liberada na circulação e pode ser mensurada por meio de métodos de imunoensaio (Hamacher et al., 2015; Sheyin et al., 2015; Tiruvoipati et al., 2012).

Sua elevação em pacientes sépticos é comum, porém seu papel para prognosticar o paciente em sepse ainda é bastante debatido (Tiruvoipati et al., 2012). Portanto, a avaliação de marcadores cardíacos, como a troponina I cardíaca, a quantificação de determinados marcadores prognósticos, como as proteínas de fase aguda, entre elas a proteína $\mathrm{C}$ reativa, e os marcadores de hipóxia tecidual, como o lactato sérico, podem ser utilizados para identificar e prognosticar o paciente séptico ou com SRIS
(Krinshnagopalan et al., 2002; Stevenson et al., 2007).

No presente estudo, objetivou-se avaliar a troponina I cardíaca como marcador de lesão cardíaca, além de outros parâmetros hematológicos, em cadelas com piometra.

\section{MATERIAL E MÉTODOS}

O estudo foi aprovado pela Comissão de Ética no Uso de Animais (CEUA) da instituição, sob o protocolo $n^{\circ}$ 034/11.

Foi realizado um estudo prospectivo entre dezembro de 2013 e abril de 2015. Inicialmente foram selecionadas cadelas oriundas da rotina do Hospital Universitário da instituição diagnosticadas com piometra e avaliadas independentemente da idade, do peso ou da raça. Foram separadas em dois grupos (sepse e não sepse). O diagnóstico de piometra foi realizado com base em sinais clínicos, no histórico, em achados ultrassonográficos, em parâmetros hematológicos e bioquímicos. A confirmação se deu posteriormente, durante o procedimento cirúrgico, por meio da realização de análise citológica para confirmação de exsudato séptico. Após o diagnóstico, foram coletadas amostras para realização das análises laboratoriais, realização de eletrocardiograma utilizando aparelho ECG PC VET, versão 6.2 - 2011 $\left(\right.$ TEB $^{\circledR}$ - Brasil), ecocardiograma por meio do aparelho My Lab 40 (Esaote ${ }^{\circledR}$ - Itália) e mensuração da pressão arterial sistólica utilizando-se aparelho Doppler Vascular modelo 811-B (Parks Medical Eletronics ${ }^{\circledR}$ - EUA). Os proprietários foram informados de todo $\mathrm{O}$ processo, sendo solicitada a assinatura de um formulário de consentimento que autorizava a realização dos procedimentos e dos exames. As pacientes foram avaliadas para a presença de sepse após exame físico e resultado do hemograma. $\mathrm{O}$ diagnóstico de sepse foi confirmado se a paciente apresentasse pelo menos dois critérios estabelecidos de acordo com Hauptman et al. (2007): hipo ou hipertermia $\left(<38,1^{\circ} \mathrm{C}\right.$ ou $\left.>39,2^{\circ} \mathrm{C}\right)$, taquicardia $(>120 \mathrm{bpm})$, taquipneia $(>20 \mathrm{mrpm})$, leucopenia ou leucocitose $\left(<4 \times 10^{3}\right.$ ou $\left.>16 \times 10^{3}\right)$ e neutrófilos jovens $>3 \%$.

As cadelas que apresentaram alguma doença cardíaca, assim como aquelas tratadas 
recentemente com medicações cardiotóxicas, doenças concomitantes ou avaliação do conteúdo uterino não compatível com piometra, foram excluídas do estudo. Dez cadelas saudáveis, oriundas da rotina do Hospital Veterinário da instituição, submetidas à cirurgia de OSH eletiva, foram incluídas como grupo controle.

Para avaliação das variáveis hematológicas, os seguintes parâmetros foram analisados: hemácias, hemoglobina, volume globular (VG), volume globular médio (VGM), concentração de hemoglobina globular média (CHGM), leucócitos totais e plaquetas. Realizou-se contagem automática por meio do aparelho IDEXX VetAutoread. As contagens diferenciais de leucócitos, a contagem global de eritrócitos e a análise morfológica foram avaliadas pelo esfregaço sanguíneo. Para análise do perfil bioquímico, foram determinadas as concentrações séricas de albumina (método verde de bromocresol), globulina (diferença entre proteína total e albumina), creatinina (método picrato alcalino), ureia (método cinético UV), fosfatase alcalina - FAL (método cinético optimizado), proteínas totais - PT (método biureto), aspartato aminotransferase - AST e alanina aminotransferase ALT (método cinético UV-IFCC). Utilizaram-se kits específicos da marca Interteck-Katal para essas análises. Para avaliação da glicemia sanguínea, foi utilizado o aparelho Accu-Check Active (Roche $\left.{ }^{\circledR}\right)$.

As amostras de sangue para mensuração da troponina I foram coletadas no dia um (consulta) e no dia 10 (retorno) e foram analisadas utilizando-se o Kit Antibody-Protein (Troponina canina 1 (TN1) Kit ELISA, Mybiosource ${ }^{\circledR}$ ).

A mensuração da proteína $\mathrm{C}$ reativa foi realizada pelo método aglutinação de partículas de látex por meio do kit Biolátex semiquantitativo Bioclin $^{\circledR}$ (igual ou superior a $6 \mathrm{mg} / \mathrm{L}$ ). Para o lactato, utilizou-se o aparelho Accutrend Lactato $\left(\right.$ Roche $^{\circledR}$ ).

Para a análise estatística, foi utilizado um delineamento em blocos ao acaso, em esquema fatorial $3 \times 2$ (três grupos, sendo animais controle, animais com piometra sepse e animais com piometra não sepse, e dois momentos de avaliação, sendo no momento da consulta e no retorno - 10 dias após a consulta). Os blocos foram constituídos pelos animais, e os tratamentos pelos três grupos experimentais. Cada parcela experimental (unidade experimental) foi representada por um cão. Os dados são apresentados como média \pm desviopadrão (DP). Após o teste de normalidade dos resíduos (Kolmogorov-Smirnov) e o de homocedasticidade das variâncias (Levene), a análise de variância (ANOVA) dos dados de avaliação clínica e laboratorial foi realizada. Quando significativos à ANOVA, os dados nos dois momentos de avaliação em cada um dos grupos experimentais foram submetidos ao teste F. Para a comparação dos dados de avaliação clínica e laboratorial nos três grupos experimentais em cada momento de avaliação, foi utilizado o teste de Tukey. Diferenças foram consideradas estatisticamente significativas quando $P<0,05$. Toda análise estatística foi realizada utilizando-se o pacote estatístico IBM ${ }^{\circledR}$ SPSS ${ }^{\circledR}$ para Windows, versão 20.0 (IBM ${ }^{\circledR}$ SPSS $®, 2011)$.

\section{RESULTADOS}

Quarenta animais foram inicialmente selecionados por se enquadrarem nos critérios de inclusão para os grupos sepse e não sepse. Destes, 21 animais foram excluídos. Dez animais apresentavam doença cardíaca primária, cinco apresentavam doenças concomitantes (hemoparasitoses, neoplasia mamária), um apresentava politraumatismo, três não compareceram ao retorno no dia estabelecido, e em três não foi confirmada piometra durante o procedimento cirúrgico. Assim, o estudo em questão foi composto por 19 animais, divididos em dois grupos: piometra sepse e piometra não sepse. $\mathrm{O}$ grupo sepse foi constituído por 12 cadelas $(63 \%)$, com idade média de 82,00 $\pm 41,52$ meses (24 - 132 meses) e peso médio de $12,75 \pm 9,47 \mathrm{~kg}$ ( 3 - $33 \mathrm{~kg})$, enquanto o grupo não sepse foi constituído por sete cadelas $(37 \%)$, com idade média de $89,14 \pm 52,24$ meses (36 - 168 meses) e peso médio de $18,43 \pm 17,29 \mathrm{~kg}$ ( $3-41 \mathrm{~kg})$. O grupo controle foi composto por 10 cadelas saudáveis,

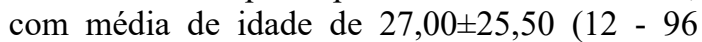
meses) e peso médio de $13,00 \pm 8,64 \mathrm{~kg}(6-29 \mathrm{~kg})$.

Não houve diferença estatística entre os grupos avaliados com relação ao peso; porém, para a variável idade dos animais (meses), observou-se que os animais do grupo controle apresentaram uma idade inferior $(\mathrm{P}<0,01)$ aos animais dos 
grupos sepse e não sepse e que, nesses dois últimos, a idade não diferiu $(\mathrm{P}>0,05)$ entre eles. As raças mais comuns nos grupos piometra foram sem raça definida (SRD) $(\mathrm{n}=6)$, Pinscher $(n=3)$, Labrador $(n=2)$, Poodle $(n=2)$, Teckel $(n=2)$, Fila Brasileiro $(n=1)$, Fox Paulistinha $(\mathrm{n}=1)$, Pastor Alemão $(\mathrm{n}=1)$, Pointer Alemão $(n=1)$. Já no grupo controle, as raças mais comuns foram SRD $(n=7)$, Labrador $(n=1)$, Teckel $(n=1)$ e Schnauzer $(n=1)$. Dos 12 animais do grupo sepse, o mesmo número de animais (quatro) apresentou cinco, quatro e três critérios para SRIS, respectivamente.

Com relação às variáveis hematológicas, houve diferença estatística significativa na contagem de leucócitos totais entre os três grupos avaliados no momento da consulta. O grupo sepse apresentou contagem de leucócitos totais significativamente mais elevada se comparado ao grupo controle e ao grupo não sepse, e o grupo controle apresentou contagem de leucócitos totais inferior ao grupo não sepse (Tab. 1).
Com relação à porcentagem de bastonetes, houve diferença estatística significativa entre os três grupos avaliados no momento da consulta, e o grupo sepse apresentou valores superiores ao grupo controle e ao grupo não sepse. Não houve diferença estatística entre estes dois grupos. Ainda com relação à porcentagem de bastonetes, o grupo sepse apresentou diferença estatística significativa na consulta se comparada ao retorno, com porcentagens superiores nesse momento da avaliação (Tab. 2). Dos 12 cães do grupo sepse, nove apresentaram valores de leucócitos superiores ao intervalo de referência e apenas um cão apresentou valor inferior. Já com relação aos valores de bastonetes, oito cães apresentaram valores superiores ao intervalo de referência. Não houve diferença significativa no número de hemácias, na saturação de hemoglobina e na quantidade de plaquetas entre os grupos, estando todos os valores dentro do intervalo de referência.

Tabela 1. Média \pm desvio-padrão (DP) da variável hematológica: leucócitos totais $\left(\mathrm{mm}^{3}\right)$ de cadelas com piometra dos grupos sepse e não sepse e de cadelas do grupo controle no dia da consulta (dia um) e no retorno (dia 10 de pós-operatório)

\begin{tabular}{|c|c|c|c|c|c|c|}
\hline \multirow{2}{*}{$\begin{array}{l}\text { Grupo } \\
\text { avaliado } \\
\text { (G) }\end{array}$} & \multicolumn{2}{|c|}{ Momento da avaliação (M) } & \multirow[t]{2}{*}{ Média } & \multicolumn{3}{|c|}{ Valor de P } \\
\hline & Consulta & Retorno & & $\mathrm{G}$ & $\mathrm{M}$ & $\begin{array}{c}G \times \\
M\end{array}$ \\
\hline Controle & $9.620,00 \pm 2.427,77 \mathrm{C}$ & $11.020,00 \pm 5.062,40 \mathrm{~B}$ & $10.320,00 \pm 3.999,02 \mathrm{C}$ & $<0,01$ & $<0,01$ & $<0,01$ \\
\hline Sepse & $32.491,67 \pm 17.804,24 \mathrm{aA}$ & $13.109,09 \pm 7.376,03 \mathrm{bAB}$ & $23.221,74 \pm 16.848,80 \mathrm{~A}$ & & & \\
\hline Não sepse & $14.928,57 \pm 7.085,49 \mathrm{~B}$ & $14.057,14 \pm 6.706,61 \mathrm{~A}$ & $14.492,86 \pm 6.828,26 \mathrm{~B}$ & & & \\
\hline Média & $20.365,52 \pm 15.865,72 \mathrm{a}$ & $12.600,00 \pm 6.504,68 \mathrm{~b}$ & & & & \\
\hline
\end{tabular}

Médias seguidas por diferentes letras minúsculas na linha diferem entre si pelo teste $\mathrm{F}(\mathrm{P}<0,05)$.

Médias seguidas por diferentes letras maiúsculas na coluna diferem entre si pelo teste Tukey $(\mathrm{P}<0,05)$.

Tabela 2. Média \pm desvio-padrão (DP) da variável hematológica: neutrófilos jovens (bastonetes) (\%) de cadelas com piometra dos grupos sepse e não sepse e de cadelas do grupo controle no dia da consulta (dia um) e no retorno (dia 10 pós-operatório)

\begin{tabular}{|c|c|c|c|c|c|c|}
\hline \multirow{2}{*}{$\begin{array}{c}\text { Grupo } \\
\text { avaliado } \\
\text { (G) }\end{array}$} & \multicolumn{2}{|c|}{ Momento da avaliação (M) } & \multirow[t]{2}{*}{ Média } & \multicolumn{3}{|c|}{ Valor de P } \\
\hline & Consulta & Retorno & & $\mathrm{G}$ & $\mathrm{M}$ & $\mathrm{G} \times \mathrm{M}$ \\
\hline Controle & $2,00 \pm 2,57 \mathrm{~B}$ & $1,30 \pm 1,29$ & $1,65 \pm 2,05 \mathrm{~B}$ & $<0,01$ & $<0,01$ & $<0,01$ \\
\hline Sepse & $9,33 \pm 13,23 \mathrm{aA}$ & $2,18 \pm 1,04 b$ & $5,91 \pm 10,18 \mathrm{~A}$ & & & \\
\hline Não sepse & $2,00 \pm 2,12 \mathrm{~B}$ & $1,86 \pm 1,01$ & $1,93 \pm 1,64 \mathrm{~B}$ & & & \\
\hline Média & $5,03 \pm 9,37 a$ & $1,79 \pm 1,18 b$ & & & & \\
\hline
\end{tabular}

Médias seguidas por diferentes letras minúsculas na linha diferem entre si pelo teste $\mathrm{F}(\mathrm{P}<0,05)$.

Médias seguidas por diferentes letras maiúsculas na coluna diferem entre si pelo teste Tukey $(\mathrm{P}<0,05)$. 
Com relação às variáveis bioquímicas, houve diferença estatística significativa na concentração sérica da FA entre os três grupos avaliados e entre os momentos de avaliação. O grupo sepse apresentou elevações mais significativas $(347,72 \pm 300,18 \mathrm{U} / \mathrm{L})$ comparado ao grupo não sepse e ao grupo controle, respectivamente (174, $71 \pm 150,93$ e $110,32 \pm 41,25)$. Dos 12 animais do grupo sepse, 10 apresentaram valores da FA superiores ao intervalo de referência. Não houve diferença estatística significativa nas concentrações séricas da PT, da albumina, da globulina, da ALT, do AST, da ureia e da creatinina entre os grupos, porém os grupos
SRIS+ e SRIS- apresentaram valores de ureia e creatinina superiores ao intervalo de referência.

Não houve diferença estatística significativa na concentração da troponina I cardíaca entre os três grupos avaliados e entre os momentos de avaliação (Tab. 3).

Com relação à mensuração da $\mathrm{PCr}$, houve diferença estatística significativa entre os três grupos avaliados. O grupo sepse apresentou elevações estatisticamente significativas quando comparado ao grupo não sepse e ao grupo controle (Tab. 4).

Tabela 3. Média \pm desvio-padrão (DP) da troponina I (ng/mL) de cadelas com piometra dos grupos sepse e não sepse e de cadelas do grupo controle no dia da consulta (dia um) e no retorno (10 dias de pósoperatório)

\begin{tabular}{|c|c|c|c|c|c|c|}
\hline \multirow{2}{*}{$\begin{array}{c}\text { Grupo avaliado } \\
\text { (G) }\end{array}$} & \multicolumn{2}{|c|}{ Momento da avaliação (M) } & \multirow[t]{2}{*}{ Média } & \multicolumn{3}{|c|}{ Valor de P } \\
\hline & Consulta & Retorno & & $\mathrm{G}$ & $\mathrm{M}$ & $\mathrm{G} \times \mathrm{M}$ \\
\hline Controle & $0,056 \pm 0,012$ & $0,056 \pm 0,012$ & $0,056 \pm 0,012$ & 0,711 & 0,937 & 0,877 \\
\hline Sepse & $0,056 \pm 0,010$ & $0,057 \pm 0,017$ & $0,056 \pm 0,014$ & & & \\
\hline Não sepse & $0,055 \pm 0,007$ & $0,053 \pm 0,011$ & $0,054 \pm 0,009$ & & & \\
\hline Média & $0,056 \pm 0,010$ & $0,056 \pm 0,014$ & & & & \\
\hline
\end{tabular}

Tabela 4. Média \pm desvio-padrão (DP) da proteína $\mathrm{C}$ reativa $(\mathrm{PCr})(\mathrm{mg} / \mathrm{dL})$ de cadelas com piometra dos grupos sepse e não sepse e de cadelas do grupo controle no dia da consulta (dia um) e no retorno (dia 10 de pós-operatório)

\begin{tabular}{ccccccc} 
Grupo avaliado & \multicolumn{2}{c}{ Momento da avaliação $(\mathrm{M})$} & Média & & \multicolumn{3}{c}{ Valor de P } \\
\cline { 2 - 3 } \cline { 6 - 7 }$(\mathrm{G})$ & Consulta & Retorno & & $\mathrm{G}$ & $\mathrm{M}$ & $\mathrm{G} \times \mathrm{M}$ \\
\hline Controle & $4,20 \pm 3,91$ & $3,00 \pm 3,05$ & $3,60 \pm 3,53 \mathrm{C}$ & $<0,01$ & 0,986 & 0,217 \\
Sepse & $15,00 \pm 25,52$ & $25,55 \pm 54,15$ & $19,57 \pm 41,69 \mathrm{~A}$ & & & \\
Não sepse & $14,57 \pm 15,71$ & $6,00 \pm 3,29$ & $10,29 \pm 12,02 \mathrm{~B}$ & & & \\
\cline { 2 - 3 } Média & $11,17 \pm 18,80$ & $12,21 \pm 35,18$ & & & & \\
\hline
\end{tabular}

Médias seguidas por diferentes letras maiúsculas na coluna diferem entre si pelo teste Tukey $(\mathrm{P}<0,05)$.

Com relação às mensurações do lactato sérico entre os grupos, houve diferença estatística significativa entre os três grupos avaliados e entre os momentos de avaliação (Tab. 5). Os grupos sepse e não sepse apresentaram resultados superiores se comparados ao grupo controle. Dos 12 animais do grupo sepse, 10 animais apresentavam concentração sérica acima dos intervalos de referência.

Tabela 5. Média \pm desvio-padrão (DP) do lactato sérico (mmol/L) de cadelas com piometra dos grupos sepse e não sepse e de cadelas do grupo controle no dia da consulta (dia um) e no retorno (10 dias de pósoperatório)

\begin{tabular}{|c|c|c|c|c|c|c|}
\hline \multirow{2}{*}{$\begin{array}{c}\text { Grupo avaliado } \\
\text { (G) }\end{array}$} & \multicolumn{2}{|c|}{ Momento da avaliação (M) } & \multirow[t]{2}{*}{ Média } & \multicolumn{3}{|c|}{ Valor de P } \\
\hline & Consulta & Retorno & & $\mathrm{G}$ & $\mathrm{M}$ & $\mathrm{G} \times \mathrm{M}$ \\
\hline Controle & $2,82 \pm 0,79$ & $2,87 \pm 0,63$ & $2,85 \pm 0,71 \mathrm{~B}$ & $<0,01$ & $<0,01$ & 0,132 \\
\hline Sepse & $4,09 \pm 1,49$ & $4,82 \pm 1,89$ & $4,44 \pm 1,72 \mathrm{~A}$ & & & \\
\hline Não sepse & $3,57 \pm 1,41$ & $4,70 \pm 1,57$ & $4,14 \pm 1,58 \mathrm{~A}$ & & & \\
\hline Média & $3,53 \pm 1,37 b$ & $4,09 \pm 1,72 \mathrm{a}$ & & & & \\
\hline
\end{tabular}

Médias seguidas por diferentes letras minúsculas na linha diferem entre si pelo teste $\mathrm{F}(\mathrm{P}<0,05)$.

Médias seguidas por diferentes letras maiúsculas na coluna diferem entre si pelo teste Tukey $(\mathrm{P}<0,05)$. 


\section{DISCUSSÃO}

Todas as cadelas com piometra deste estudo foram adequadamente diagnosticadas e se enquadraram na classificação de sepse proposta por Hauptman et al. (2007). O coração é um dos órgãos mais afetados pela resposta que ocorre na sepse ou no choque séptico em cadelas com piometra (Maretta et al., 1989), podendo acarretar depressão miocárdica. Como a troponina I é uma proteína encontrada apenas no coração e é expressa unicamente pelas células do miocárdio (Dunn et al., 2011), levantou-se a hipótese, neste trabalho, de que essa proteína poderia ser um biomarcador precoce de dano ao miocárdio.

Quando ocorre um dano à célula do miocárdio, a troponina é liberada na circulação e pode ser mensurada por meio de métodos de imunoensaio (Hamacher et al., 2015; Sheyin et al., 2015; Tiruvoipati et al., 2012). No atual estudo, as concentrações séricas da troponina I cardíaca não demonstraram diferença estatística significativa entre o grupo controle e o grupo piometra sepse ou não sepse, diferindo de Pelaner et al. (2008), em que houve diferença significativa na concentração da troponina I em cadelas com piometra se comparadas ao grupo controle. Hamacher et al. (2014) e Langhorn et al. (2014), em estudos realizados em cães com SRIS, também demonstraram diferença estatística nas concentrações séricas da troponina I, revelando aumento significativamente maior no grupo não sobrevivente quando comparado ao grupo sobrevivente.

No trabalho de Takasu et al. (2013), porém, realizado com o intuito de avaliar o grau de morte dos cardiomiócitos na sepse, não foram observadas evidências de lesão aguda irreversível ou morte celular em amostras cardíacas de pacientes sépticos. A microscopia eletrônica revelou incidência de lesão focal na membrana das mitocôndrias dos cardiomiócitos no grupo controle e em pacientes sépticos.

Com base nesses achados de Takasu et al. (2013), pode-se justificar os resultados do trabalho em questão e inferir que a sepse não induz a morte celular significativa dos cardiomiócitos, mas sim alterações consistentes de lesão mitocondrial, o que indica que a morte celular é uma condição pouco comum na disfunção cardíaca induzida pela sepse, mesmo com lesão mitocondrial.

No presente estudo, não houve elevação da concentração da troponina I, possivelmente por não ter ocorrido injúria miocárdica a ponto de causar a morte celular. Outra possibilidade seria a de que os pacientes deste estudo, embora tenham atendido aos critérios de sepse, não entraram em choque séptico, quadro este que provavelmente poderia causar danos maiores às células cardíacas.

Dessa forma, pode-se inferir que a troponina pode não ser considerada um biomarcador precoce de depressão miocárdica, pois apresenta valores aumentados apenas quando há lesão dos cardiomiócitos. Segundo Maretta et al. (1989), a depressão miocárdica é uma das principais causas de morte em cadelas com piometra, mas pode-se concluir que essa depressão não ocorre por morte de cardiomiócitos e que outros mecanismos, como, por exemplo, a deformação cardíaca, possam ser o mecanismo de disfunção cardíaca.

Em relação aos parâmetros hematológicos e bioquímicos, no presente estudo, observaram-se consideráveis alterações nas cadelas com piometra se comparadas aos animais do grupo controle. As alterações significativas $(\mathrm{P}<0,05)$ foram observadas nos valores da contagem total de leucócitos, da enzima fosfatase alcalina e na porcentagem de neutrófilos jovens (bastonetes). De acordo com Fransson et al. (2004) e Jitpean et al. (2014), em estudos utilizando cadelas com piometra, também foram encontradas alterações marcantes no perfil hematológico e bioquímico, o que leva a concluir que são achados esperados nessa doença.

A presença de leucocitose com neutrofilia e desvio à esquerda, um dos parâmetros que mais demonstraram alterações no estudo em questão e em estudos semelhantes, pode ser explicada como uma estimulação que ocorre na medula óssea devido ao processo inflamatório, à resposta ao estresse e à resposta de fase aguda (Patil et al., 2013).

Condições inflamatórias sistêmicas envolvem liberação acentuada de citocinas (Karlsson et al., 2013). No presente estudo, as concentrações séricas da $\mathrm{PCr}$ demostraram alterações 
significativas entre os três grupos avaliados. O grupo controle apresentou concentração sérica inferior quando comparado ao grupo piometra. Segundo Clyne e Olshker (1999), a PCr é uma proteína de fase aguda e já está bem estabelecido que a sua elevação na circulação é fortemente associada a condições inflamatórias em humanos e em cães; no entanto, foi demonstrado que a $\mathrm{PCr}$ apresenta capacidade limitada para diferenciar quadros sépticos de outras condições inflamatórias em humanos.

Ishida et al. (2011), em um estudo semelhante com cães apresentando SRIS de origem infecciosa e não infecciosa, observaram que as concentrações séricas da $\mathrm{PCr}$ mostraram-se elevadas. Isso reflete que a $\mathrm{PCr}$ pode ser considerada um marcador sensível para a SRIS, porém não é necessariamente específica para sepse devido ao fato de sua concentração também estar elevada em condições inflamatórias de outras etiologias (Jitpean et al., 2014).

No presente estudo, a elevação nos níveis de lactato, previamente definidos como $>2,5 \mathrm{mmol} / \mathrm{L}$ por McMichael et al. (2005), esteve presente em 17 das 19 cadelas com piometra (11/12 grupo sepse e 5/7 grupo não sepse), indicando diminuição da perfusão tecidual. Ainda segundo McMichael et al. (2005), a hipóxia tecidual pode ser originada por várias causas, como hipoperfusão, anemia ou edema tecidual. Condições de hipovolemia, mau funcionamento hepático com diminuição da absorção de lactato podem induzir hiperlactatemia e consequente acidose láctica. A acidose láctica pode estar presente em quadro de sepse em que há aumento na produção do lactato a partir do baço ou de outros órgãos. Esses dados explicam os achados das cadelas com piometra no trabalho em questão.

O presente estudo apresenta algumas limitações; a primeira delas refere-se ao número limitado de animais incluídos. Alguns animais tiveram que ser excluídos devido à falta de colaboração de seus proprietários ao não comparecerem ao retorno no dia estabelecido, outros foram excluídos por apresentarem doença cardíaca primária ou doenças concomitantes. Uma segunda limitação refere-se ao estado clínico e à variação individual dos pacientes incluídos. Para minimizar essa variação individual, foram utilizados os critérios para sepse. No entanto, esses critérios são inespecíficos, uma vez que animais excitados ou estressados podem satisfazer mais de um desses critérios.

\section{CONCLUSÕES}

Os resultados indicam que a troponina I não pode ser considerada um biomarcador precoce para injúria miocárdica nos casos de cadelas com sepse secundária à piometra, pois os resultados das mensurações foram semelhantes entre os grupos, inferindo que pode não haver lesão dos cardiomiócitos nessa fase. Já a proteína $\mathrm{C}$ reativa e o lactato são possíveis marcadores para inflamação sistêmica, uma vez que demonstraram concentrações séricas significativamente maiores em cadelas com piometra.

\section{AGRADECIMENTOS}

Á Fundação de Amparo a Pesquisa do Estado de Minas Gerais (Fapemig), ao Conselho Nacional de Desenvolvimento Científico e Tecnológico $(\mathrm{CNPq})$ e à Coordenação de Aperfeiçoamento de Pessoal de Nível Superior (Capes), pelo financiamento concedido.

\section{REFERÊNCIAS}

ABRAHAM, E.; MATTHAY, M.A.; DINARELLO, C.A. Consensus conference definitions for sepsis, septic shock, acute lung injury, and acute respiratory distress syndrome: time for a reevaluation. Crit. Care Med., v.28, p.232-235, 2000.

CLYNE, B.; OLSHKER, J.S. The $\mathrm{C}$ reative protein. J. Emerg. Med., v.17, p.1019-1025, 1999.

DUNN, M.E.; COLUCCIO, D.; HIRKALER, G. et al. The complete pharmacokinetic profile of sérum cardiac troponin $\mathrm{I}$ in the rat and the dog. Toxicol. Sci., v.132, p.368-373, 2011.

FRANSSON, B.A.; KARLSTAM, E.; BERGSTROM, A. et al. C-reactive protein in the differentiation of pyometra from cystic endometrial hyperplasia/mucometra in dogs. J. Am. Anim. Hosp. Assoc., v.40, p.391-399, 2004.

HAGMAN. R. Diagnostic and prognostic markers for uterine diseases in dogs. Reprod. Domestic Anim., v.49, p.16-20, 2014. 
HAMACHER, L.; DCORFELT, R.; MULLER, M. et al. Serum cardiac troponin i concentrations in dogs with systemic inflammatory response syndrome. J. Vet. Int. Med., v.29, p.164-170, 2015.

HAUPTMAN, J.; WALSHAW, R.; OLIVIER, N. Evaluation of the sensitivity and specificity of diagnostic criteria for sepsis in dogs. Vet. Surg., v.26, p.393-397, 1997.

ISHIDA, A.; OHNO, K.; FUKUSHIMA, K. et al. Plasma high-mobility group box 1 (HMGB1) in dogs with various diseases: comparison with C-reactive protein. J. Vet. Med. Sci., v.73, p.1127-1132, 2011.

JITPEAN, S.; HOLST, B.S.; HÖGLUND, O.V. et al. Serum insulin-like growth factor-I, iron, Creactive protein, and serum amyloid $\mathrm{A}$ for prediction of outcome in dogs with pyometra. Theriogenology, v.82, p.43-48, 2014.

KARLSSON, I.; WERNERSSON, S.; AMBROSEN, A.; et al. Increased concentrations of C-reactive protein but not high-mobility group box 1 in dogs with naturally occurring sepsis. Vet. Immunol. Immunopathl., v.156, p. 64-72, 2013.

KRINSHNAGOPALAN, S.; KUMAR, A.; PARRILO, L.E. Myocardial dysfunction in the patient with sepsis. Curr. Opin. Crit. Care, v.8, p.376-388, 2002.

LANGHORN, R.; THAWLEY, V.; OYAMA, M.A. et al. Prediction of long-term outcome by measurement of serum concentration of cardiac troponins in critically ill dogs with systemic inflammation. J. Vet. Int. Med., v.28, p.14921497, 2014.

MARETTA, S.M.; MATTHIESEN, D.T.; NICHOLS, R. Pyometra and its complications. Probl. Vet. Med., v.1, p.50-62, 1989.
MCMICHAEL, M.; LEES, G.; HENNESEY, J. et al. Serial plasma lactate concentration in 68 puppies aged 4 to 80 days. J. Vet. Emerg. Crit. Care, v.15, p.17-21, 2005.

PATIL, A.R.; SWAMY, M.; CHANDRA, A. et al. Clinico-haematological and serum biochemical alterations in pyometra affected bitches. Afr. J. Biotechnol., v.12, p.1564-1570, 2013.

PELANER, L.; HAGMAN, R.; HÄGGSTROM, J. Concentrations of cardiac Troponin I before and after ovariohysterectomy in 46 female dogs with pyometra. Acta Vet. Scand., v.50, p.1-8, 2008.

RABELO, R.C. Sepse, sepse grave e choque séptico. In: RABELO, R.C. Emergências de pequenos animais: condutas clínicas e cirúrgicas no paciente grave. Rio de Janeiro: Elsevier, 2012. p.322-340.

SHEYIN, O.; DAVIES, O.; DUAN, W. et al. The prognostic significance of troponin in patients with sepsis: a meta - analysis. Heart Lung, v.44, p.75-81, 2015.

SPSS $^{\circledR}$ statistics for windows. Version 20.0, Release 0.0.0. Armonk, New York: IBM Corp., 2011.

STEVENSON, C.K.; KIDNEY, B.A.; DUKE, T. et al. Serial blood lactate concentrations in systemically ill dogs. Vet. Clin. Pathol., v.36, p.234-239, 2007.

TAKASU, O.; GAUT, J.P.; WATANABE E. $e t$ al. Mechanisms of cardiac and renal dysfunction in patients dying of sepsis. Am. J. Resp. Crit. Care Med., v.187, p.509-517, 2013.

TIRUVOIPATI, R.; SULTANA, N.; LEWIS, D. Cardiac troponin I does not independently predict mortality in critically ill patients with severe sepsis. Emerg. Med. Australasia, v.24, p.151-158, 2012. 